\title{
THE PUBLIC HEALTH SERVICES AND VENEREAL DISEASES
}

By L. W. HARRISON, D.S.O., M.B., Ch.B., F.R.C.P.E., BrevetColonel, R.A.M.C. (Ret.).

IN I9I6, the Government, accepting the recommendations of the Royal Commission on Venereal Diseases, undertook the task of restricting the spread of these diseases by the method of rendering non-infective the greatest possible number of the infected population. The Public Health Regulations, I9I6, were accordingly issued by the Local Government Board, now the Ministry of Health, requiring county and county borough councils in England and Wales to formulate schemes for the treatment of persons suffering from syphilis, gonorrhœa or soft chancre, and the Medical Officer of the Local Government Board circulated a memorandum of suggestions for the guidance of these councils.

The main lines of operation, as contemplated in the regulations and the memorandum of the Medical Officer of the Local Government Board, have been as follows :-

(I) The setting up of centres for the gratuitous treatment of persons suffering from syphilis, gonorrhœa or soft chancre in early and at all communicable stages.

(2) The provision for treatment centres and private practitioners of facilities for the free examination of pathological specimens from persons known or suspected to be suffering from any of the three diseases mentioned above.

(3) The gratuitous supply of arsenobenzol compounds for the treatment of syphilis to private practitioners who are qualified to administer these drugs.

(4) The education of the public in the dangers of these diseases and the importance of prompt and skilled treatment and advertisement of the treatment facilities provided by the public health service. 


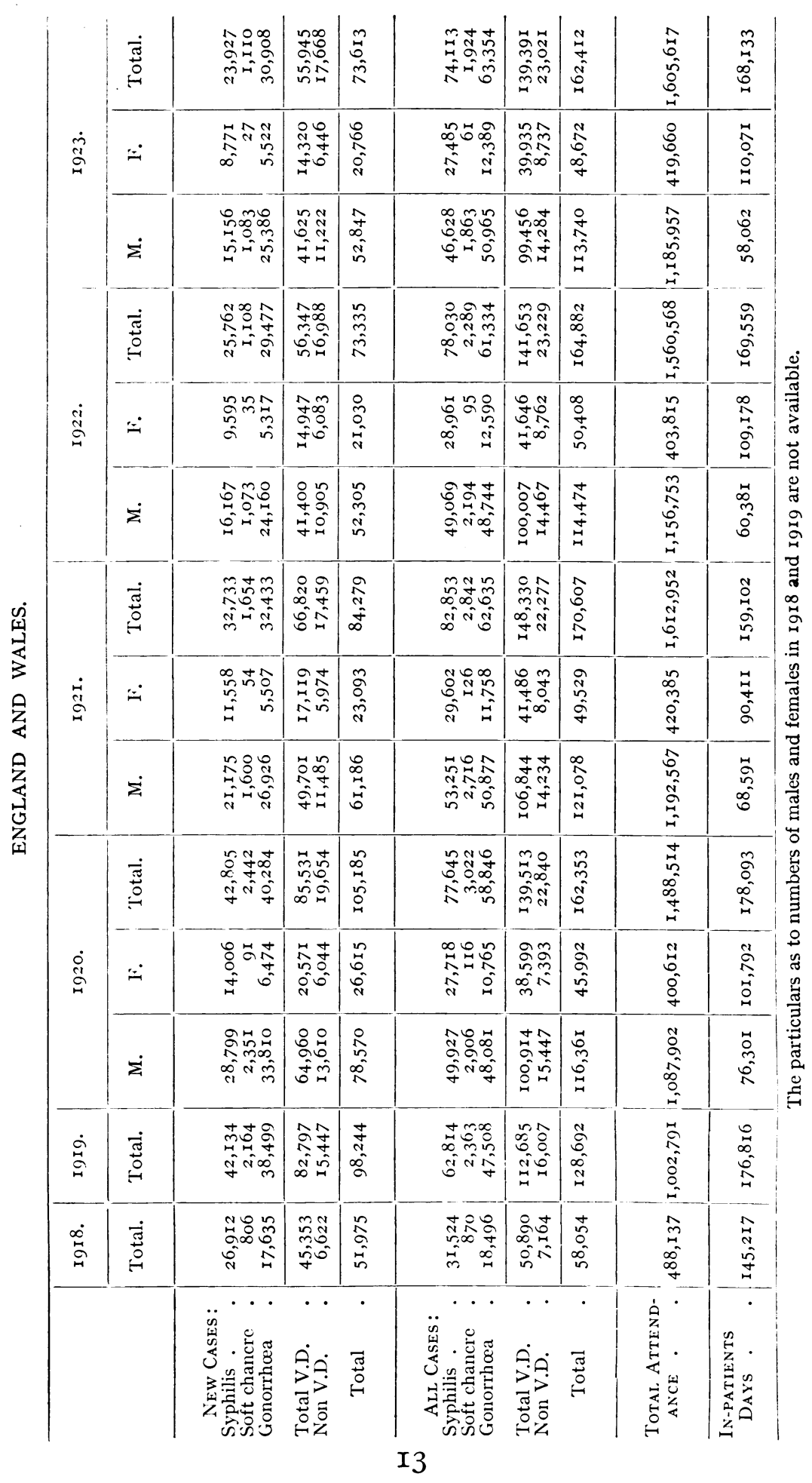

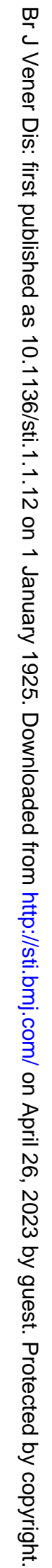




\section{BRITISH JOURNAL OF VENEREAL DISEASES}

Similar arrangements for Scotland have been made by the Scottish Board of Health.

The work which has been done on these lines by the county and county borcugh councils in England and Wales has been as follows:

There are now I93 treatment centres, of which 142 are in voluntary hospitals and $5 \mathrm{I}$ in institutions, such as tuberculosis dispensaries, directly under the control of the public health authority. Thus the great majority of the treatment centres are in voluntary hospitals, in accordance with the recommendations of the Royal Commission.

Where centres have been established in institutions directly under the public health authority, it has generally been because the local hospital authorities have not cared to undertake the work, or because after they have undertaken it, the arrangement has not proved satisfactory.

The work of the treatment centres during the years I9I9-23 is shown in the table on page I3.

In addition, fourteen hostels, with an accommodation of approximately 250 beds, have been established for the care of girls suffering from venereal diseases who are temporarily homeless and who might become prostitutes unless helped out of their difficulties. As a rule, the girls remain until fit to return to work and, where possible, this employment has been found for them. At some of these hostels arrangements have been made for the reception of pregnant women suffering from venereal disease. In addition, there are five special institutions for this purpose. In I923 more than I,000 women and girls were treated in hostels and in these special institutions.

The propaganda work has been largely carried out by the National Council for Combating Venereal Diseases, which was the organisation recommended by the Royal Commission for this purpose. The National Council has its headquarters in London, where general propaganda is organised, and branches in various parts of the country which form a connecting link between the mother society and the local health authorities.

Some local authorities organise their own propaganda, and most undertake the work of advertising the treatment facilities in their own localities.

The cost of the work in England and Wales, of which 75 per cent. is borne by the Government and the balance 


\section{BRITISH JOURNAL OF VENEREAL DISEASES}

by the county and county borough councils, has been approximately as follows :-

\begin{tabular}{|c|c|c|c|}
\hline I920-2I & - & • & 470,000 \\
\hline I92I-22 & - & - & - $45^{2,000}$ \\
\hline I922-23 & - & - & . 399,000 \\
\hline
\end{tabular}

Of these amounts, approximately 82 per cent. was for treatment centres, I2 per cent. for laboratory examinations, I.5 per cent. for the supply of arsenobenzol compounds to private practitioners, 2 per cent. for propaganda, and 2.5 per cent. for other services.

This briefly is a description of the scheme, and of some of its results, and the question arises whether the scheme is fulfilling the object for which it was set up. Also, if not entirely successful, where improvements are desirable.

A partial answer to these questions can be found in the work of the treatment centres shown above, where it will be seen that since I920 there has been a very definite decline in the number of new cases of syphilis. The decline might possibly be due to an increasing proportion of patients seeking the advice of private practitioners, but this seems to be contradicted by the fact that, in spite of the tendency to administer more doses of arsenobenzol compound to each case of syphilis, the cost of arsenobenzol supplied to practitioners has decreased. Also the increasing proportion of applicants for advice who were apprehensive that they might be suffering from venereal disease, but were found not to be infected, indicates a growing popularity of the centres with the public. Altogether, it seems fair to infer from the figures of the treatment centres that there has been a real decrease in the incidence of syphilis in the general population. Indeed the decline may be greater than appears from the figures, since a substantial proportion of the new cases of syphilis (by new cases is meant those reporting for the first time during the year in question) were infected many years before the venereal diseases scheme came into operation. In respect, therefore, of acquired syphilis, the indications are that the venereal disease scheme is proving a success.

With regard to congenital syphilis, no figures are available which make it possible to draw any conclusions, but as my strong impression is that its incidence is higher than it might be, I will deal with it below when suggesting 


\section{BRITISH JOURNAL OF VENEREAL DISEASES}

the lines on which the working of the scheme could be improved.

In the case of gonorrhœa, the treatment centre figures indicate that we are still far from our goal. The ratio of gonorrhœa new cases to those of syphilis has never approached that which we have reason to believe represents the ratio of infections. During the War, I calculated that the ratio of gonorrhœal infection to syphilitic in the British Army in France and Flanders was $2 \frac{1}{2}$ or 3 to I, and the notifications of these diseases in Scandinavia are approximately five of gonorrhœa to one of syphilis. It seems right to conclude that by no means such a high proportion of persons suffering from gonorrhœa as of syphilis are being treated at the centres. It may be that more are being treated by private practitioners, but there are strong grounds for suspecting that an important proportion of these patients are treating themselves or, in spite of the Venereal Diseases Act, I9I7, which forbids the treatment of venereal diseases by unqualified persons, are resorting to quacks.

Recognising that in regard to gonorrhœea and congenital syphilis there is need for improvements in the working of the venereal diseases scheme, I propose to suggest in what follows the lines on which these could be effected.

The comparatively poor progress which has been made in the combating of gonorrhoea may be partly due to the lightness with which many persons still regard this disease, but the indifferent treatment which the patients not infrequently receive from medical attendants cannot be acquitted of blame. It is still the belief of many medical men that no better results can be obtained in gonorrhœa to-day than half a century or more ago. The belief is a comfortable one since the old treatment does not require the doctor to rise from his consulting-room chair, seated on which he can tell the patient to purchase a syringe and can write a prescription for lotion, capsules and medicine. It is easy to claim for it a respectable proportion of cures for which the real credit is due to the natural tendency of the patients' tissues to throw out the infecting organism. Out of the remainder, those who in fact become chronic carriers of the gonococcus, it is easy enough to claim as cures a substantial percentage of cases by accepting the patients' statements that their discharge has ceased; by 


\section{BRITISH JOURNAL OF VENEREAL DISEASES}

examining patients merely for expressible discharge, perhaps half an hour or less after they have urinated, or by lightly attributing a chronic gleet to " post-gonorrhœal catarrh." If, in these uncured cases, the discharge becomes too obvious to be ignored after the astringent effect of the injections has worn off, it is very often possible to blame a fresh sexual indiscretion on the part of the patient, and so by one or other method of deceiving himself the practitioner's mind is left at ease. In contrast to this comfortable form of management, the socalled modern treatment of gonorrhœa is laborious to a degree, both physically and mentally, and its results unfortunately gain no credit with the casual observer, who judges the result by the duration of apparent discharge from the urethra. If, however, the test of the microscope and the culture tube is applied, and if any return of discharge is attributed to its true cause, the results of the older forms of treatment make a sorry showing. There is little doubt, in fact, that they do nothing to sterilise the very type of case which is responsible for the spread of gonorrhœa, the chronic gonococcus carrier. Moreover, the practice of the older forms of treatment of gonorrhoa deters other patients from attending. The turnover of a treatment centre depends to some extent on its reputation, and, if patients find that they receive little better in the form of treatment than they could apply to themselves, they are not likely to advise their friends to resort to the centre. This can be proved by a comparison of the records of new cases and of defaulters shown by centres staffed by medical officers who practise modern methods, and by those who follow the easier practice of ancient times. Between the practitioners of the old school and those of the modern is an intermediate class. The members of this have heard that sounds are often passed for the cure of chronic gonorrhœa, that prostatic massage and instillations have often proved useful, and that cures have been claimed for vaccines. Accordingly, when the patient's signs still persist, without examining to discover the site of the residuum of disease, they prescribe one or all of these methods of treatment in the hope, presumably, that one or other shot in the dark may hit the target. The innocent posterior urethra and prostate are often punished by these practitioners for an infected follicle in the anterior urethra, and the patient's gleet continues 


\section{BRITISH JOURNAL OF VENEREAL DISEASES}

until he becomes tired of attending. We shall make progress in our attack on gonorrhœea only when the large majority, or all, of the medical officers of treatment centres realise that they are there not merely to relieve patients of their symptoms, but take the hard path and spare no effort to discover and sterilise the areas of the genito-urinary passage where the infection persists, so as to prevent infection of other members of the public.

The temptation to practise treatment by medicines and lotions and nothing else is often strengthened by the inconvenience of the conditions for carrying out the modern scientific methods, and for this much of the responsibility lies at the door of hospital authorities, who persist in considering that the loan of a few rooms in their out-patient departments for a few hours per week is all that their duty to the public requires of them in return for a contribution to their funds, which, coming from a private individual, would almost produce a red carpet on each of his arrivals at the hospital. Under such conditions the task of the medical officer who is determined to do everything possible to sterilise his gonorrhœal patients is indeed hard, and there is little wonder that so many take the line of least resistance. Fortunately there are many medical officers whose high sense of public duty stimulates them to triumph over difficulties, and as their numbers are growing we can hope for better results.

I would appeal to the remainder to follow their example by doing their utmost not only for the syphilitic but also for the gonococcus carrier. 'I would appeal to hospital authorities to fulfil the duties they have undertaken in connection with this public health measure by making it as easy as possible for medical officers charged with the treatment of venereal diseases to carry out their work. It is surely the duty of a hospital which has agreed with the public health authority to open a treatment centre for venereal diseases to maintain one which is reasonably adapted to the purpose for which it is created. Where the hospital willingly helps the medical officer and the medical officer is playing his part, we are making progress in the campaign against gonorrhœa. Where the reverse holds, it is clear that it would be useless continuing if it were not for the hope that some day a better and fairer spirit may prevail.

The case of congenital syphilis is bound up with the I 8 


\section{BRITISH JOURNAL OF VENEREAL DISEASES}

securing of contacts. It raises the question of the views which medical officers of venereal disease treatment centres take of the purpose of their work. Some time ago I saw in a treatment centre a patient with a chancre of the thumb. I asked the medical officer if this man had been warned that for some time he would be in danger of conveying the disease to his wife. The medical officer did not think it part of his duty to give the man any such warning and talked of the risk of causing domestic disturbances. This medical officer evidently regarded his duties as beginning and ending with the relief of the individual patient. My view that he was not merely an outpatient officer, but a member of the public health service, appointed for the purpose of protecting the public health in certain particulars, was quite new to him, and in this case his patient's wife was probably a victim of the medical officer's limited conception of his duties. At the same session I saw a man and his wife who had been sent by their family doctor for anti-syphilitic treatment because the wife had given birth to an infant which had just died of congenital syphilis, this being the fourth such failure in a few years. The man's history was that he had contracted syphilis in I9I9 and had been treated quite regularly in another centre for nearly two years, but in the whole of this time he had received no advice to have his wife examined and, if necessary, treated. This was, after all, a fortunate outcome of such a neglect of duty. A worse would have been the birth in that family of one or more children who did not die soon (thus solving their life's problem comfortably and easily) but grew up to an age when they became blind and deaf, or possibly mentally defective, burdens to themselves and on the community. Congenital syphilis is a reproach. Every one connected with the medical profession knows, or ought to know, that a newly-infected married man need not convey the disease to his wife if the proper safeguards are taken, yet it is greatly to be feared that many such men are not advised on this point, or that, if there is the slightest suspicion that infection has been transmitted, they should have their wives examined. Again, it is well known that syphilis is a potent cause of stillbirths and deaths in very early infancy. Conversely, such a history in the family should stimulate the medical man, or the midwife, to urge on the parents the necessity 


\section{BRITISH JOURNAL OF VENEREAL DISEASES}

of at least being examined with a view to the prevention of such disasters in future. If such were the custom with those who have the medical care and nursing of women in childbirth, there would surely be a great reduction in the incidence of congenital syphilis. The arguments which can be used in persuasion are so strong that they must succeed in a high proportion of cases. Even if a woman is unconcerned about the sequence of failures in the form of miscarriages, still-births and infants who die early, she cannot fail to respond to the warning that a syphilitic child may survive early childhood to become blind, deaf, mentally defective, or in some other way crippled by syphilis in later childhood or adolescence.

Ophthalmia neonatorum is still too prevalent in spite of prophylactic instillations after birth. Yet, judging by results where it is practised, ante-partum treatment of women suffering from gonorrhœa seems to be wonderfully successful in preventing conveyance of infection to the eyes of the infant. In my own centre, from June, I92I, to the end of September, I924, there were treated I3I pregnant women suffering from gonorrhœa, and the results as regards the condition of the infant's eyes are known in II8. Out of these there occurred three cases of conjunctivitis and nine of ophthalmia neonatorum; of the twelve, eight (six O.N.) were born of forty-nine mothers who first applied for treatment later than the sixth month. The attendance of these mothers was good in four cases, fair in one, and poor in three. Out of sixtynine infants born of mothers who applied for treatment before the sixth month, one developed conjunctivitis and three ophthalmia neonatorum. The attendance of the mothers had been good in one case, fair in one, and poor in two. No eye was lost or damaged.

I suggest that, in their capacity as officers of the public health service, medical officers of venereal disease treatment centres and of maternity and child welfare centres could do much to prevent ophthalmia neonatorum by sparing no effort to secure adequate examination, and treatment if necessary, of all women suffering from vaginal discharge. I mean not merely advising the examination, but urging it and taking some pains to see that the advice is followed. Incidentally, such ante-partum treatment would probably reduce the incidence of puerperal fever which is still not negligible in spite of the aseptic toilet of 


\section{BRITISH JOURNAL OF VENEREAL DISEASES}

all instruments and parts outside the vagina. Perhaps I might persuade those who are more interested in preventing puerperal fever than ophthalmia neonatorum to do that which will reduce the incidence of ophthalmia if I suggest that, for one mild germ they destroy on hands, gloves, instruments and external genitals, there are often a million within the vagina of the kinds found in puerperal septicæmia, and with a virulence which is raised above the normal by reason of being concerned in a mild cervical catarrh. It will be said that it is hopeless to expect that women would consent to such examinations. This is tantamount to saying that it is hopeless to expect to convince the medical profession of their value, because as soon as the profession becomes convinced of the necessity of a health measure and preaches it energetically any such

o difficulties with the lay public quickly begin to disappear.

“ The chief obstacle to any health measure is public ignor-

$\therefore$ ance of its reason and necessity, and this opens the last of the points on which I can touch in this sketch. A prime necessity in combating venereal diseases by treatment is to secure the attendance of the greatest possible number of the infected population. The average human being habitually forgets until reminded, and the constant $\lambda$ reminder in the form of propaganda and advertisement of $x$ facilities for treatment can easily be proved to have a most

$\sim$ powerful effect in increasing the attendance at treatment $\checkmark$ centres. On a chart of attendances in my own centre the $\checkmark$ effect of advertisement is easy to see. A high rise corresponds to a period when the centre happened to be specially advertised in underground lavatories, a very well marked depression corresponds to a period when the London treatment centres were hardly advertised at all, and a later rise began when the advertisements of the centres were resumed. It is, of course, a business axiom that a good thing must be well advertised, and the same applies to treatment centres. The better they are advertised, the more certainly we shall succeed in getting under treatment all the infected members of the population.

It need hardly be added that it is not enough to secure new cases. The attendance of these until rid of their infection is vital, and not the least important means of insuring continuance of attendance is consideration for the patients' feelings and convenience. The average patient suffering from venereal disease is not mentally 


\section{BRITISH JOURNAL OF VENEREAL DISEASES}

defective, and is quick to resent any attitude which suggests that he is in any way a pariah.

These are a few ways in which I think we could improve our attack on venereal disease. They indicate that all members of the public health service-and in this I would include medical officers of treatment centres, some of whom are too apt to regard themselves merely as surgeons and physicians to out-patients-must lose no opportunity of bringing under treatment any member of the community whom they suspect may have venereal disease, and must spare no pains to ensure the sterilisation of the infection of those who do attend. Merely to relieve them of symptoms does not fulfil the object we have in view, and the medical officer who regards his duty as completed at this stage might just as well leave the work alone for all the use he is to the public health. 